\title{
COMPLETELY MONOTONIC FUNCTIONS RELATED TO GURLAND'S RATIO FOR THE GAMMA FUNCTION
}

\author{
Chao-Ping Chen And Junesang Choi
}

Abstract. The subject of complete monotonicity for functions has gained considerable popularity and importance from a rather long ago up to now, due mainly to its demonstrated applications in getting diverse inequalities. Here, we investigate some completely monotonic functions related to Gurland's ratio for the gamma function. Certain relevant connections of the results presented here with those earlier ones are also pointed out. Further, an interesting open conjecture regarding our present concern is posed.

Mathematics subject classification (2010): Primary 33B15, Secondary 26A48.

Keywords and phrases: Gamma function, psi function, polygamma functions, completely monotonic function, Gurland's ratio.

\section{REFERENCES}

[1] M. Abramowitz AND I. A. Stegun (Eds), Handbook of Mathematical Functions with Formulas, Graphs, and Mathematical Tables, National Bureau of Standards, Applied Mathematics Series 55, 9th printing, Washington, 1970.

[2] H. Alzer and C. Berg, Some classes of completely monotonic functions, Ann. Acad. Sci. Fenn. Math. 27 (2002), 445-460.

[3] J. Dubourdieu, Sur un théorème de M. S. Bernstein relatif à la transformation de Laplace-Stieltjes, Compositio Math. 7 (1939), 96-111.

[4] J. Gurland, A inequality satisfied by the gamma function, Skand. Aktuarietidiskr. 39 (1956), 171 172.

[5] H. VAn Haeringen, Completely monotonic and related functions, J. Math. Anal. Appl. 204 (1996), 389-408.

[6] R. L. Joshi AND T. R. FISCHER, Comparison of generalized Ganssian and Laplacian modeling in DCT image coding, IEEE Signal Proe. Letters 2 (1995), 81-81.

[7] M. MERKLE, Gurland's ratio for the gamma function, Comp. Math. Appl. 49 (2005), 389-406.

[8] K. SHARIFI AND A. LEON-GARCIA, Estimation of shape parameter for generalized Ganssian distribution in subband decomposition of video, IEEE Trans. Circ. Syst. Video Techn. 5 (1995), 52-56.

[9] H. M. SRIVAStaVA AND J. ChOI, Zeta and q-Zeta Functions and Associated Series and Integrals, Elsevier Science Publishers, Amsterdam, London and New York, 2012.

[10] E. W. STACY, A generalization of gamma distribution, Ann. Math. Statistics 28 (1962), 1187-1192.

[11] D. V. WidDER, The Laplace Transform, Princeton University Press, Princeton, 1941. 